\title{
Estimating spatially distributed soil texture using time series of thermal remote sensing - a case study in central Europe
}

\author{
Benjamin Müller ${ }^{1,2}$, Matthias Bernhardt ${ }^{1}$, Conrad Jackisch ${ }^{3}$, and Karsten Schulz ${ }^{1}$ \\ ${ }^{1}$ Institute of Water Management, Hydrology and Hydraulic Engineering, University of Natural Resources and Life Sciences, \\ Vienna, Austria \\ ${ }^{2}$ Department of Geography, Ludwig-Maximilians-Universität, Munich, Germany \\ ${ }^{3}$ Institute of Water and River Basin Management, Karlsruhe Institute of Technology, Karlsruhe, Germany
}

Correspondence to: Matthias Bernhardt (matthias.bernhardt@boku.ac.at) and

Benjamin Müller (b.mueller@iggf.geo.uni-muenchen.de)

Received: 8 March 2016 - Published in Hydrol. Earth Syst. Sci. Discuss.: 4 April 2016

Revised: 2 August 2016 - Accepted: 22 August 2016 - Published: 12 September 2016

\begin{abstract}
For understanding water and solute transport processes, knowledge about the respective hydraulic properties is necessary. Commonly, hydraulic parameters are estimated via pedo-transfer functions using soil texture data to avoid cost-intensive measurements of hydraulic parameters in the laboratory. Therefore, current soil texture information is only available at a coarse spatial resolution of 250 to $1000 \mathrm{~m}$.

Here, a method is presented to derive high-resolution $(15 \mathrm{~m})$ spatial topsoil texture patterns for the meso-scale Attert catchment (Luxembourg, $288 \mathrm{~km}^{2}$ ) from 28 images of ASTER (advanced spaceborne thermal emission and reflection radiometer) thermal remote sensing. A principle component analysis of the images reveals the most dominant thermal patterns (principle components, PCs) that are related to 212 fractional soil texture samples. Within a multiple linear regression framework, distributed soil texture information is estimated and related uncertainties are assessed. An overall root mean squared error (RMSE) of 12.7 percentage points (pp) lies well within and even below the range of recent studies on soil texture estimation, while requiring sparser sample setups and a less diverse set of basic spatial input.

This approach will improve the generation of spatially distributed topsoil maps, particularly for hydrologic modeling purposes, and will expand the usage of thermal remote sensing products.
\end{abstract}

\section{Introduction}

The prediction of (sub-)surface water and solute transport processes, from the plot to the basin scale, heavily rely on spatial information of soil hydraulic properties (SHPs). However, the measurement of SHPs in the field or in the lab is very time-consuming and expensive with regard to equipment and labor costs (Durner and Lipsius, 2005). To reduce experimental efforts and cost, SHPs are often estimated via so-called pedo-transfer functions from other soil properties available that are easier and cheaper; examples of relevant properties are soil texture, bulk density or organic carbon content (Pachepsky and Rawls, 2004).

Standard soil texture information, from country to global levels, is available from a variety of sources. They vary in resolution, method of production and quality. Exemplary soil texture sources on country to global level are JRC (2015), FAO (2015), ISRIC (2015), USDA (2015) or AAFC (2010). The spatial resolutions of these products differ between 250 and $1000 \mathrm{~m}$. The product quality is defined by usually sparse sample data and additional spatial information ranging from topography, landform observations, remote sensing products or expert knowledge. Furthermore, applied interpolation techniques and landscape evolution models, as well as pattern estimation methods, control the quality of derived spatial soil texture products. In general, texture information has a coarse spatial resolution and partly consist only of qualitative information; thus, this information is characterized by large uncertainties that are hard to quantify. 


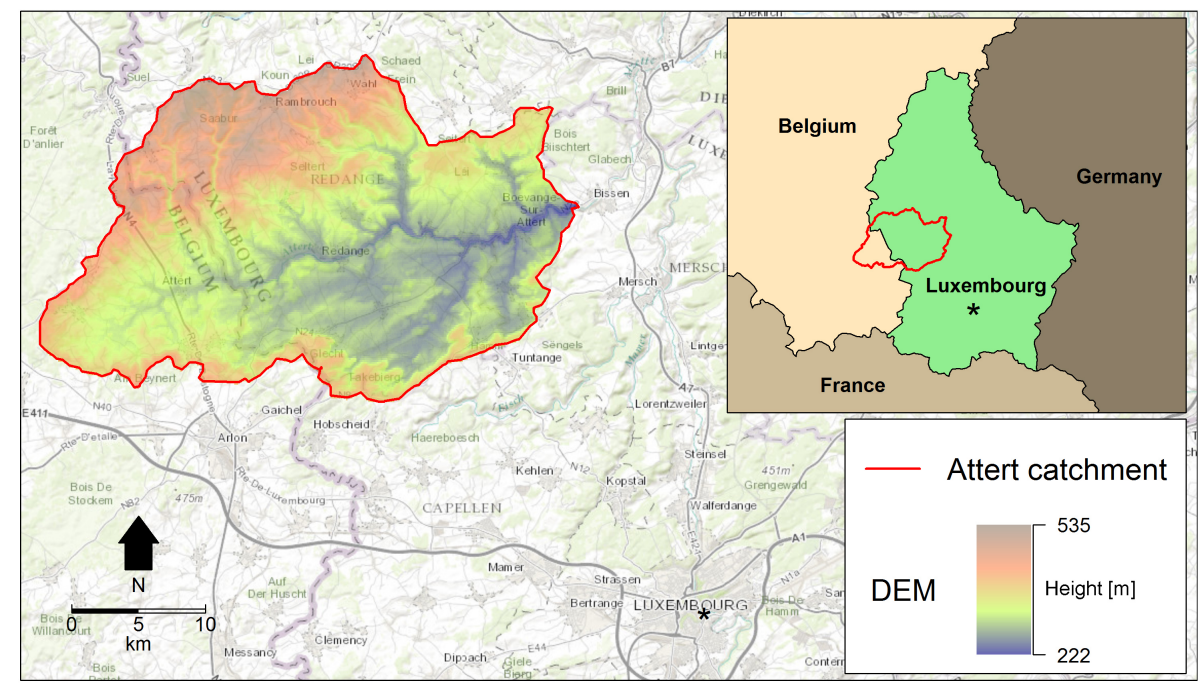

Figure 1. The position of the Attert catchment with superimposed elevation data. The gauge Bissen, Luxembourg, defines the catchment boundaries.

However, many current applications, e.g., land surface models, heavily rely on high-resolution products in the range of $100 \mathrm{~m}$ and less (precision farming: 10-50 m, e.g., Selige et al. (2006), or Sadler et al. (1998); flood forecasting: 50100 m, e.g., de Roo et al. (2003), or Reed et al. (2007)). Any quantification of uncertainties with regard to map information is missing most of the time, but would be essential in order to evaluate the quality and reliability of model predictions.

This study uses thermal remote sensing (RS) data in combination with plot measurements to generate spatially distributed soil texture maps. Physical relations between surface temperature, thermal radiation, soil water content and soil texture have been widely demonstrated in studies to determine soil texture characterizations (diurnal temperature range: Wang et al., 2015; multispectral data: Ahmed and Iqbal, 2014; partial regressions with thermal spectra: Dhawale et al., 2015). If time series of thermal RS data are available, the concept of thermal inertia is applicable to gain information on soil texture. Thermal inertia is the spatially varying tendency of the land surface to resist changes in temperature forced by energy input. Responsible for these spatial differences in inertia are patterns of thermal conductivity, density and specific heat capacity of the land surface material (Rees and Rees, 2013; Minacapilli et al., 2012). However, thermal observations of land surface are nonlinear integrals over all three dimensions in space of the occurring materials (Hall et al., 1995; Betts et al., 1996). These integrals consider spatial averaging, as well as thermal emission and propagation from subsurface thermal sources up to vegetation. Parameters that influence the surface temperature are incoming radiation, land use, albedo and available water content. Especially the latter is strongly controlled by soil texture, which subsequently should influence the thermal inertia signature as given by the temporal patterns of surface temperature.

In a previous investigation, Müller et al. (2014) utilized principal component analysis (PCA) for a statistical extraction of dominant patterns within an ASTER (advanced spaceborne thermal emission and reflection radiometer) thermal infrared (TIR) time series. The produced principal components (PCs) are independent and will be used here to derive stable patterns that are related to soil texture classes. A multilinear regression estimator (MLRE) is used in this context. The MLRE is able to establish and estimate a functional relationship between the PCs and the fractional texture information from multiple soil texture samples within a catchment. The resulting spatially high-resolution soil texture maps are analyzed for their plausibility, estimator robustness and uncertainty.

The rest of the manuscript is organized as follows: Sect. 2 introduces the test site, the implemented and auxiliary data, as well as methods applied and developed. Section 3 shows and discusses the results of the estimator setups and its crossvalidation (CV). Finally, Sect. 4 reviews main findings and gives overall conclusions.

\section{Data and methods}

\subsection{Test site}

The research area for this case study is the Attert catchment (mid-western Luxembourg, Fig. 1), the target site of the German DFG research project CAOS (Catchments as Organised Systems) (CAOS, 2015; see also Zehe et al., 2014). The catchment has a size of $288 \mathrm{~km}^{2}$ for the gauge in Bissen and stretches from 222 to $535 \mathrm{~m}$ above sea level. Collated in for- 

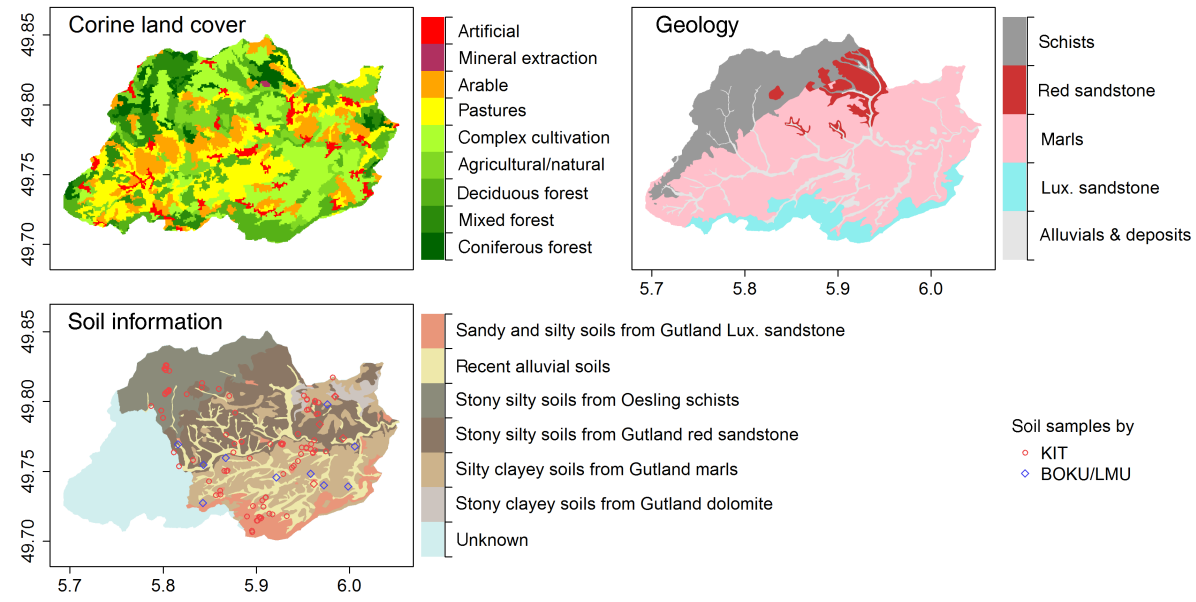

Sandy and silty soils from Gutland Lux. sandstone

Recent alluvial soils

Stony silty soils from Oesling schists

Stony silty soils from Gutland red sandstone

Silty clayey soils from Gutland marls

Stony clayey soils from Gutland dolomite

Soil samples by

- KIT

BOKU/LMU

Unknown

Figure 2. Corine land cover (upper left panel), geology data (upper right panel) and agriculturally relevant soil information (bottom left panel) of the Attert catchment. The sites of the two sample sets are marked for KIT (Karlsruhe Institute of Technology; red circles) and BOKU/LMU (University of Natural Resources and Life Sciences/Ludwig-Maximilians-Universität; blue diamonds).

mer studies (Müller et al., 2014), a spatial data set containing land cover, geology, elevation data and qualitative agricultural soil information is available (see Fig. 2). A schist massif in the north and sandstone lifts in the far south embrace the undulating central marl area (SGL, 2003). The dominant land use is agriculture $(65.4 \%)$, followed by forests $(29.7 \%)$ and settlements and other sealed areas $(4.8 \%)$ (Corine land cover; EEA, 1995). The monthly mean temperature ranges from $0^{\circ} \mathrm{C}$ in January to $18^{\circ} \mathrm{C}$ in July (1971-2000); the climate is pluvial oceanic.

The existing agricultural soil map (1: 100000 ; SPP, 1969; Fig. 2, bottom panel) lacks quantitative descriptions but give hints of spatial patterns of soil texture and its systematic distribution: silt explicitly occurs in four out of the six existent soil classes in the area; clay soils are observed in the northwest and sandy soils occur in the southeast. Thus, relations between geology and soil can be observed, particularly for schists and clay in the northwestern region, and sandstone and sand in the southeastern region.

\subsection{Soil data}

In all, 212 soil samples were taken within the first $15 \mathrm{~cm}$ of the topsoil mineral horizon during different fieldwork activities throughout the Luxembourg part of the Attert catchment (Fig. 2, lower panel). Project members from KIT (Karlsruhe Institute of Technology) took 125 out of these samples as undisturbed ring samples of $250 \mathrm{~mL}$ volume for various hydro-pedologic analyses and as reference samples for runoff-modeling purposes. The other 87 samples were taken by project members from BOKU/LMU (University of Natural Resources and Life Sciences, Vienna/LudwigMaximilians-Universität, Munich) from 30 sites in an attempt to close spatial and systematic gaps between the existing sample plots as disturbed ring samples of $250 \mathrm{~mL}$ volume for measuring soil texture. The latter sites were chosen based on agricultural soil classes, geology and land use information trying to cover the full spectrum of different classes and the full catchment extent. These sites were sampled multiple times within a radius of $1 \mathrm{~m}$ to achieve information on local uncertainty. The texture samples were analyzed based on sieving and sedimentation analysis after ISO 11277 (2009) in two different laboratories at the KIT and LMU. Due to slight differences in standards with regard to removal of organic compounds and the use of suspension aids, the data were linearly homogenized by analyzing eight samples in both laboratories and correcting the small biases with linear models for the three fractions.

The resulting texture distribution is given in Fig. 3. The samples are visualized within the classification system of the USDA. The sampled textures consist of merely high silt fractions (mainly 40-60\%), lower clay fractions (mainly 20$40 \%)$ and a wide range of sand fractions $(0-80 \%)$. The dominant soil types are silty clay loam (SiClLo), loam (Lo) and clay loam (ClLo).

Data from sites with multiple measurements (up to three samples per site) are not aggregated and, hence, include local uncertainties within a radius of $0.5 \mathrm{~m}$ for soil texture. From the multiple sampled sites, an average local standard deviation of the samples of $4.9 \mathrm{pp}$ for clay fractions can be found; for silt and sand variations are slightly higher with $7.8 \mathrm{pp}$ and $8.7 \mathrm{pp}$, respectively (overall: $7.1 \mathrm{pp}$ ). It is noticeable that the local standard deviation is half the size of the deviation of the full sample data set with $8.5 \mathrm{pp}$ for clay, $14.2 \mathrm{pp}$ for silt and $18.9 \mathrm{pp}$ for sand (overall: $16.7 \mathrm{pp}$ ). 


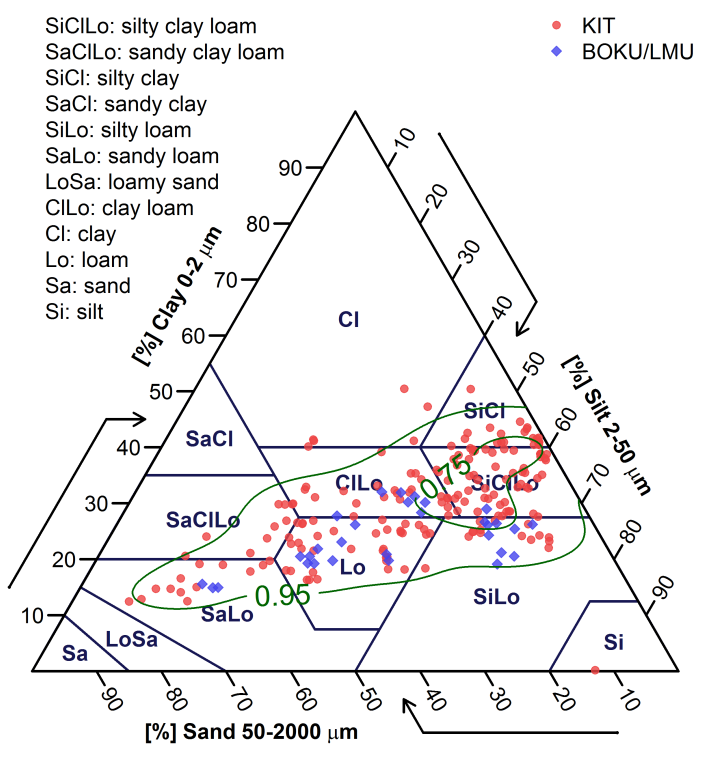

Figure 3. The categorical distribution of the homogenized soil samples by KIT (red circles) and BOKU/LMU (blue diamonds) is noted within the USDA classification scheme. The symbols are semitransparent to better visualize accumulations. Data from both laboratories overlap properly. Additionally, the estimated probability density is shown in dark green as contours for quantiles of the theoretical distribution of observable soil textures. The 0.95 contour delimits the area, $95 \%$ of the textures are lying within; the 0.75 contour defines $75 \%$ of the textures.

\subsection{Remote sensing data and deduction of principle components}

We used the ASTER instrument on board of the TERRA satellite (Fujisada, 1995) in the course of this study. The satellite has a sun-synchronous orbit, with a repetition rate from 4 to 16 days, passing the catchment at 11:40 CET. As described in Müller et al. (2014), channel 13 (10.25$10.95 \mu \mathrm{m})$ is used exclusively, as thermal signals in this wavelength are least altered by absorption in the atmosphere. The remote sensing time series then is processed for reaching $15 \mathrm{~m}$ resolution geo-referenced top-of-atmosphere (TOA) temperatures (see Müller et al. (2014), for details). The used ASTER data set consists of 28 snow and rather cloud free images from the period January 2001 to June 2012 (Fig. 4, lower panel). Figure 4 illustrates four exemplary TOA temperature images from the time series with representative patterns for each season (Fig. 4a-1 to a-4) and the available dates (Fig. 4b). Winter is under-represented with two images, as images with snow cover but no cloud cover are rare. Half of the images (15) are from spring months; summer and autumn are represented by six and five images, respectively. Based on optical data, it was found that the largest fraction of bare soil in the area is found in late spring, late summer and early autumn (15 images are covering these situations).
Based on the 28 TOA temperature time series data, PCs (PC1-PC28) are calculated as described in Müller et al. (2014). The components of a PCA are orthogonal and represent linear-independent spatial patterns. They are ranked by the proportion of explained variance in the original temperature pattern time series, which gives information on their dominance and stability within the whole time series. The PCs do not contain specific information about spatial autocorrelation of the patterns but inherit the interior organization from the thermal time series.

Müller et al. (2014) could show some relation between the most dominant PCs and observable patterns of land use or geology. The first five most dominant PCs are illustrated exemplarily in Fig. 5; it can be observed that with increasing numbering, the explained variance and pattern immanent gradients of component values decrease. PC1 and PC2 show similarities to the Corine land cover pattern and geology pattern (Fig. 2), comprehensively described by Müller et al. (2014). To avoid any influence from highly modified surfaces where no influence of soil texture on the TOA temperature can be expected, artificially covered areas (Fig. 2, upper left panel, in red) are cut out from the PCs based on Corine land cover data.

\subsection{Multiple linear regression estimator}

The relationship between soil texture data of the collected soil samples and PCs derived from time series of TIR data is analyzed by multiple linear regression. Three main steps are executed to provide soil texture maps, individually for each particle size fraction. First, an automatically parameterized Box-Cox transformation (BCT) is performed to the particle size fraction data in order to guarantee normality of the residuals (Box and Cox, 1964; Sakia, 1992; Osborne, 2010; Chun and Griffith, 2013). Then, PCs are chosen based on their significance level ( $p$ values from $F$ tests) for the multiple linear regression (MLR). At last, the results of the MLRE are restricted to values between 0 and $100 \%$ for each particle size fraction with a sigmoidal capping function on top of the MLR.

Overall, the MLR is set up by

$\hat{x}_{\lambda}=\beta_{0}+\beta_{1} \mathrm{PC} 1+\beta_{2} \mathrm{PC} 2+\cdots+\beta_{n} \mathrm{PC} n+\epsilon$,

with the PCs PC1 ... PCn, the corresponding regression coefficients $\beta_{0 . \ldots n}$ and residuals $\epsilon$ to estimate the soil texture fraction $\hat{x}_{\lambda}$. For an unbiased estimation of $\beta_{0 \ldots n}$, the residuals $\epsilon$ have to be normally distributed $N(0, \sigma)$ (Chun and Griffith, 2013).

The BCT is applied by

$x_{\lambda}^{\prime}=\left\{\begin{array}{ll}\frac{x^{\lambda}-1}{\lambda}, & \lambda \neq 0 \\ \ln (x), & \lambda=0\end{array}\right.$,

where $x$ is the soil data before transformation, $x^{\prime}$ after transformation and $\lambda$ is a parameter estimated from the data or 
error distribution to achieve normality. An optimal $\lambda$ is estimated by an iterative Monte Carlo procedure allowing $\lambda$ to range between $[-5,5]$ with an accuracy of 0.01 to guarantee finding a global minimum. Tests for normality of the residuals are executed subsequently.

To restrict the MLR predictions to the natural limits of 0-100\% share of a fraction, sigmoidal capping functions (Franklin, 2013) are used. A sigmoidal function generally is differentiable, with a non-negative $(S)$ or non-positive $(Z)$ first derivative, one minimum and one maximum. The presented approach uses the following implementation:

$\operatorname{sig}(x)=L+(U-L) \cdot \begin{cases}\left(1-e^{\left.-\left(\frac{x-s p}{s l}\right)^{2}\right),},\right. & \text { if } x \geq s p \\ L, & \text { else }\end{cases}$

where $L$ and $U$ are the lower and upper limits (here: 0 and $100 \%), s p$ is the position of the start of the positive gradient and $s l$ adapts the steepness of this gradient. These two gradient parameters are optimized for reducing the root mean square error between corrected regression estimator and sample data as much as possible.

\subsection{Cross-validation}

$\mathrm{CV}$ is a common strategy for the evaluation of model performance and the quantification of uncertainties (Arlot and Celisse, 2010). CV schemes can differ in the size of training and validation subsamples. Here, four different CV schemes are applied to analyze potential changes in the uncertainty level resulting from different sample sizes: First, a simple leave-one-out (LOO) strategy was applied, where all but one sample point are included for model identification, and the remaining data points are used for model evaluation. This procedure is repeated so that each point $(n=212)$ is left out once, and model performance in form of the root mean squared error (RMSE) between measurement and prediction can be calculated.

Three further CV variants are applied to analyze the effect of sample size reduction on the prediction performance. For this, the sample size is divided into 10\%- (CV10), $20 \%-(\mathrm{CV} 20)$ and 50\%-sized (CV50) validation subsets with respectively 90-, 80- and 50\%-sized training subsets. The random process of validation-set-generation is repeated $n=212$ times in order to have an equal number of evaluations for all CV variants. The performance of the MLRE prediction during validation is again evaluated using the RMSE for each particle class.

\section{Results}

\subsection{Sample data and soil texture maps}

First, $F$ tests were performed to evaluate the MLRE model performance with regard to the number of different PCs considered as regressors, as well as to all possible combinations of PCs (for a given number of regressors). The $p$ value of the $F$ tests represents the probability of the (soil texture) data given the null hypothesis $\left(H_{0}\right)$ that all regression coefficients are zero. Low $p$ values are taken as an overall indication for the "relevance" of the MLRE. Results showed that significant $p$ values $(<0.05)$ occurred most often when the first five PCs were incorporated, whereby a number of three PCs out of the first five components performed best. Lowest $p$ values for sand are assessed with a MLR based on PC1, PC2 and PC3; for silt, the most adequate combination is PC2, PC4 and PC5 and for the determination of clay PC2, PC3 and PC4 are used (given the full data set)

The results of the MLRE are illustrated in Fig. 6. Upper panels show the distribution contours of the $95 \%$ (red) and $75 \%$ quantiles (blue) for the estimation of different particle fractions, while the lower panels show the respective distribution of residuals. Sand and clay show higher Pearson correlation coefficients $(r>0.5)$, while silt is showing a lower value $(r=0.36)$. The optimal $\lambda$ values for the BCT indicate almost normally distributed residuals for clay, while for silt, the error distribution is skewed left, and for sand the distribution is skewed right. The overall RMSE for the three texture fraction estimators is $12.7 \mathrm{pp}$, partitioned into 16.2 pp for sand, $13.0 \mathrm{pp}$ for silt and 7.1 pp for clay. Hence, the MLR shows a well-defined relation for clay, while sand shows good correlations with few extreme outliers. For silt the system shows low correlations with a smaller variation of errors (compare Wang et al., 2015).

The MLRE calibrated with the complete field sample set is then used to calculate fully distributed texture maps. Figure 7 shows the resulting soil texture maps. Each texture fraction is modeled separately with the aforementioned PC combination. Finally, the three texture fractions are translated into USDA soil types, which are then mapped back into the catchment (Fig. 7, lower right panel). A comparison of predicted and observed texture data shows a large overlap between both (Fig. 7, lower left panel).

The distribution of soil texture conforms to the distribution of the soil characteristics displayed in the available qualitative agricultural soil maps (Fig. 2). Clay is dominant in the north, rather sandy soils can be found in the south and mainly silty soils prevail in the remaining parts of the catchment. Further analysis of the soil texture distribution reveals relations to topographic structures, different land cover types and geology (Figs. 1 and 2). The distribution of different modeled soil textures change along slopes from top (fine) to bottom (coarse) or between riparian (sandy) and agricultural (silty) areas. Clay soil mainly appears in schist areas. 

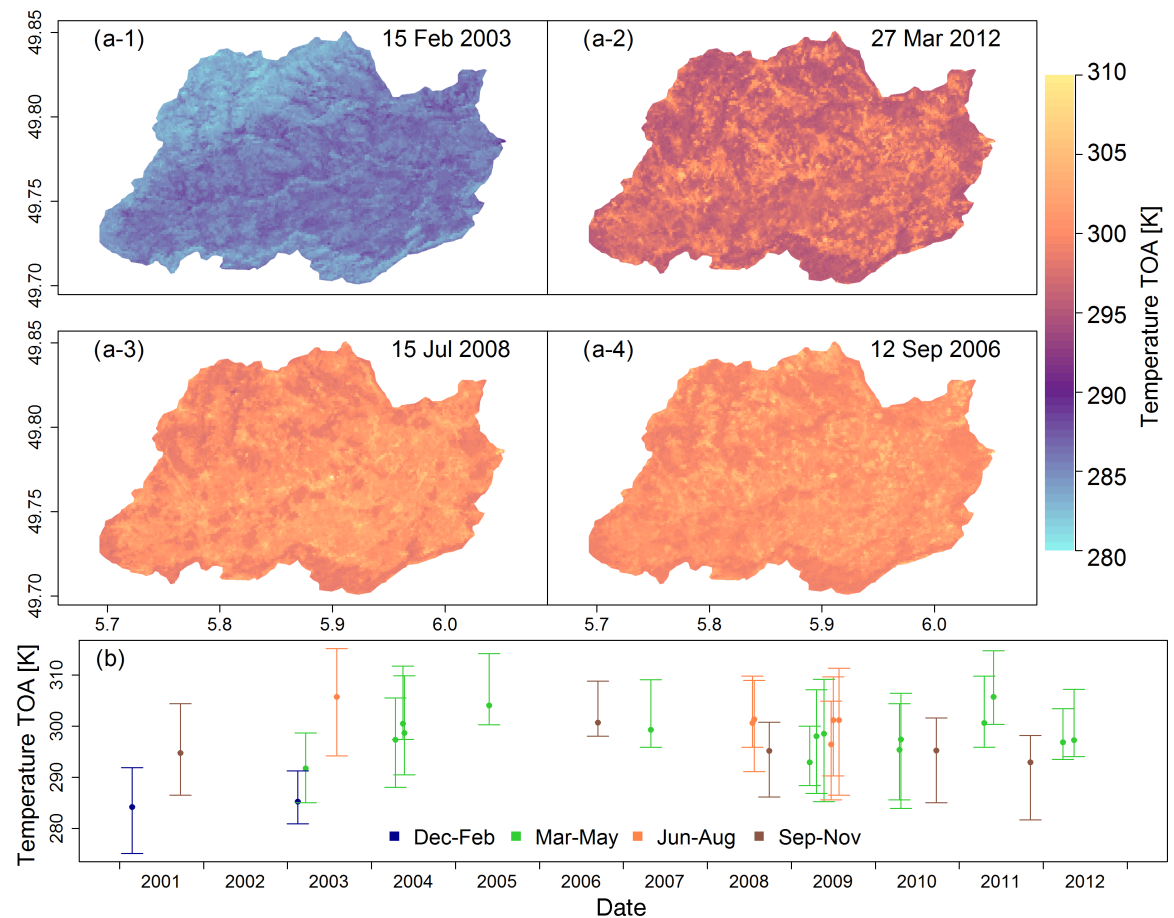

Figure 4. (a) Seasonal examples of the temperature time series patterns (winter 1, spring 2, summer 3 and autumn 4). (b) Overview of the dates of the TIR image time series show some statistical information (mean and absolute ranges).

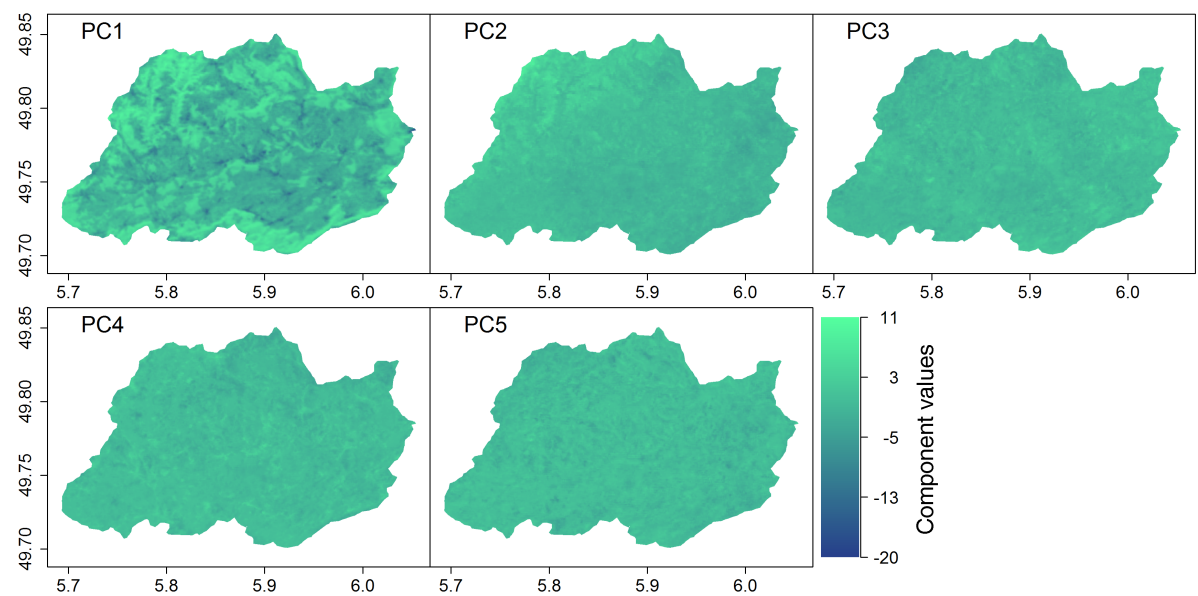

Figure 5. The first five components of the PCA of time series data, sorted by decreasing explained variance.

\subsection{Cross-validation results}

Figure 8 shows the spatial patterns of pixel-based standard deviation of the resulting 212 maps of soil texture fraction. For each different $\mathrm{CV}$ variant as well as for all $212 \mathrm{CV}$ runs, an $F$ test-based selection for the choice of PCs as described in 3.1 has been performed. The mean texture fraction results from the CV runs, e.g., CV50 (Fig. 8), agree with the overall result and differences in absolute texture fraction are small when compared to results illustrated in Fig. 7. The patterns of valley structures and bedrock distribution can be observed here as well.

Statistical indices allow further analysis of the similarities. The spatial average of the coefficient of variation (c.o.v.; $|\sigma / \mu|$ ) between all model results, i.e., from CV schemes and the full data set, shows values of below of 0.1 for all texture fractions and underlines the visual impression of small deviations. Supported by the constant RMSE values throughout different variants of the CVs (sand: $\sim 16.6 \mathrm{pp}$, silt: $\sim 13.4 \mathrm{pp}$, clay: $\sim 7.2 \mathrm{pp}$; compare Table 1), MLREs indicate a stable 

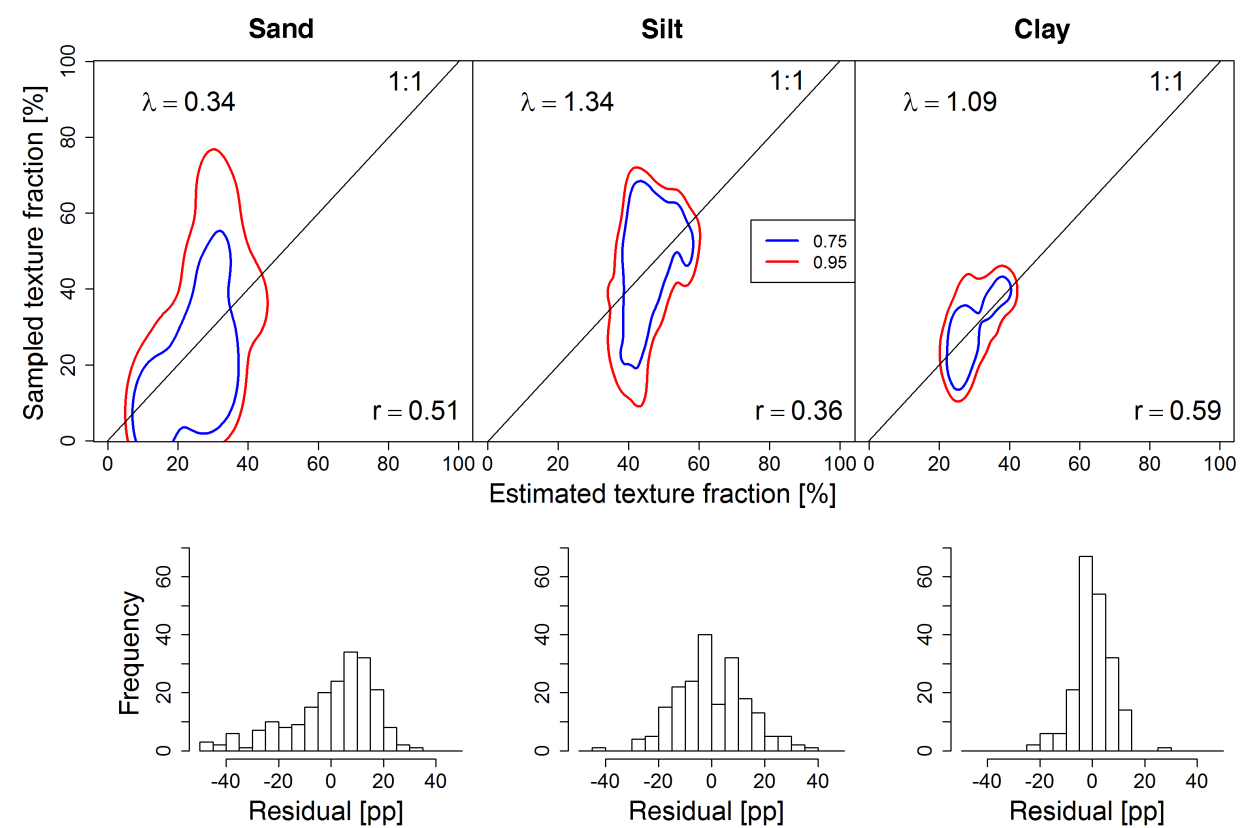

Figure 6. MLRE results for predicting sand, silt and clay fractions estimated with three components of the PCA data. The distribution contours (upper panels) show the sampled versus the estimated texture data after BCT and sigmoidal capping; $95 \%$ (red outline) and $75 \%$ quantiles (blue outline) are shown. $\lambda$ values of the BCT (upper left panel) and Pearson correlation coefficient $r$ between the sample and estimator data (lower right panel) are also noted. The lower panels show the respective distributions of residuals [estimator - data] and their skewness related to the BCT $\lambda$ values after back transformation.
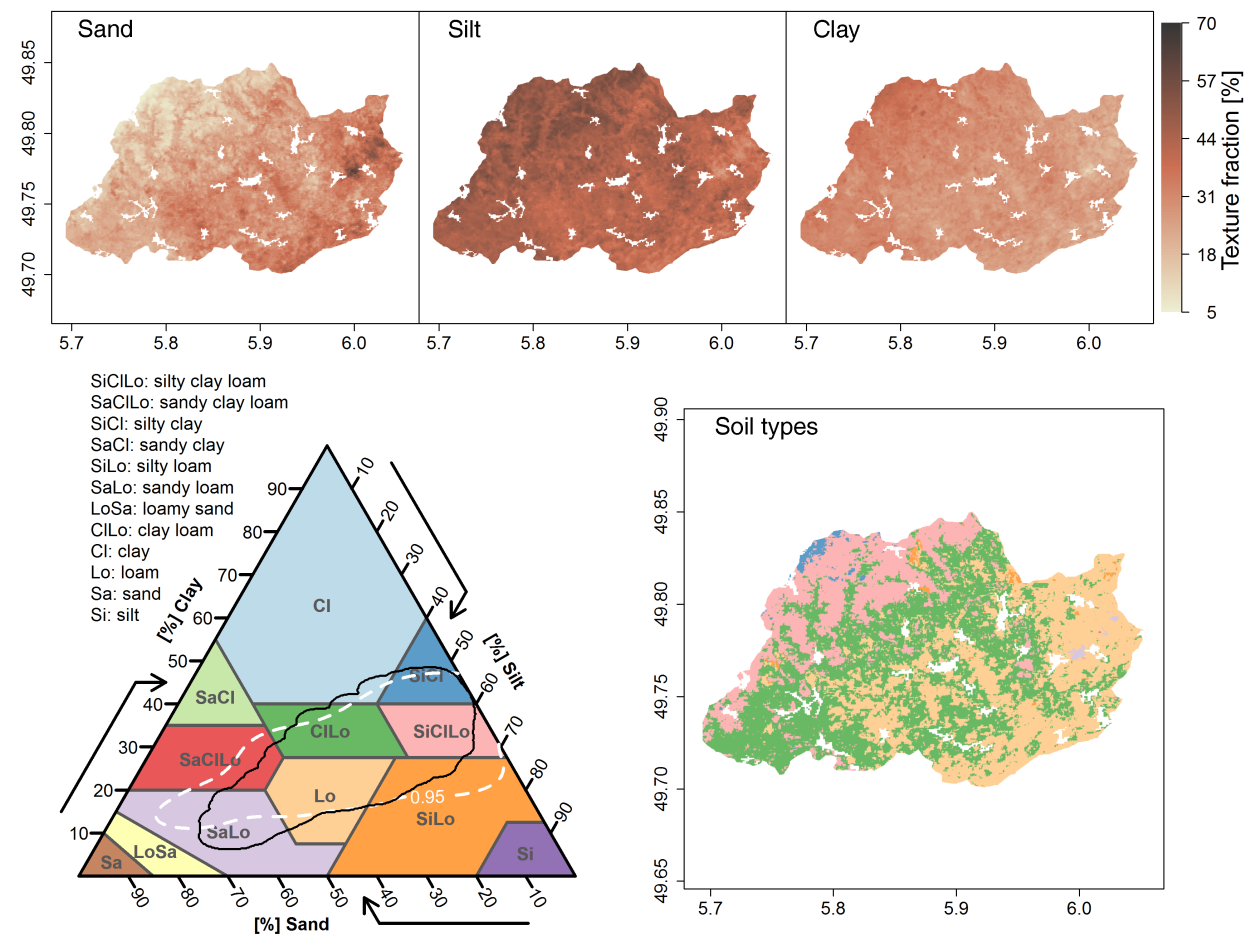

Figure 7. Result maps for texture fractions for the MLRE predictions based on the full data set are shown (upper panels). Lower left panel: texture triangle with the resulting data distribution (black outline) compared to the $95 \%$-quantile distribution estimation of the measured samples (dashed white) from Fig. 4, providing the color legend for the soil type map (lower right). Therein, artificial areas (from Corine land cover) are ignored (white). 


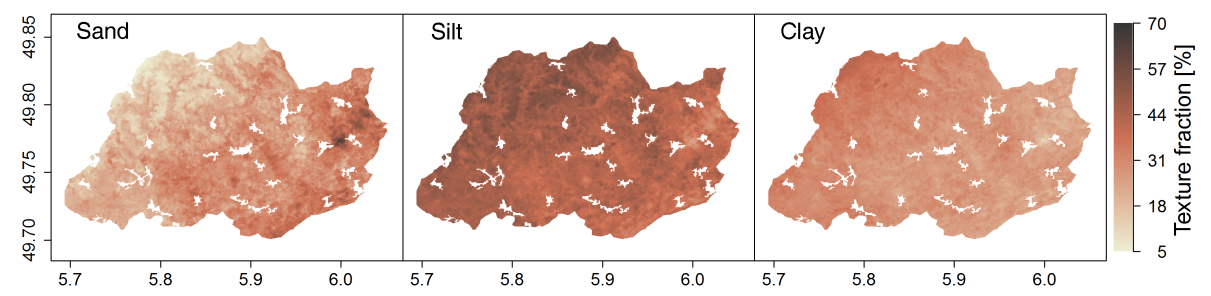

Figure 8. Exemplary mean value maps of soil texture fractions estimated with the CV50 CVS from the possible 212 different data sets. There are no significant differences between the different mean value maps for the different CVSs. Moreover, differences to the maps based on the full sample set are minor (compare Fig. 7).

Table 1. Root mean square error (RMSE) values for the sample data from the different cross-validation $(\mathrm{CV})$ variants by particle size and overall. The results are noted in percentage points (pp). The different CV variants (LOO, CV10, CV20 and CV50) show similar values for the RMSEs between sample and estimated fractions sand, silt and clay within the 212 subsets for the CVS (column 24). Additionally, the approximately constant overall RMSE for all fractions and samples within the CVs' subsets is noted (column 5).

\begin{tabular}{lcccc}
\hline & \multicolumn{3}{c}{ RMSE per particle size (pp) } & Overall \\
\cline { 2 - 4 } CV & Sand & Silt & Clay & RMSE (pp) \\
\hline LOO & 16.58 & 13.37 & 7.18 & 10.80 \\
CV10 & 16.64 & 13.42 & 7.25 & 10.87 \\
CV20 & 16.56 & 13.30 & 7.11 & 10.80 \\
CV50 & 16.89 & 13.54 & 7.34 & 11.00 \\
\hline
\end{tabular}

behavior in the estimation of spatial texture fraction. The overall RMSE for the different CVs is around $10.9 \mathrm{pp}$ and hence a little lower than for the full data set $(12.7 \mathrm{pp})$. However, silt and sand fractions are higher by ca. $0.5 \mathrm{pp}$ and clay by ca. $0.15 \mathrm{pp}$.

These values indicate higher uncertainties for silt and sand fractions. This uncertainty is attributed to a higher variation in distribution characteristics within the sample data sets that is increased by decreasing the number of used samples. Another possible source for this high uncertainty is the small thermal gradient within the range of widely different silt fractions at common surface temperatures (Farouki, 1982). This gradient is most sensitive to a low number of measurements.

In contrast to the stable mean results, textural standard deviation in Fig. 9 varies more. Clay fraction maps show least deviation, whereas the highest deviation is observed in leastsampled sandstone areas in the southeast of the catchment and the lower lands near the gauge. CV-based uncertainties occur as expected: maximum standard deviations rise with increasing size of the validation data sets, and therefore less calibration data.

Exceptional high deviations are highly localized throughout the subsets and show areas of higher uncertainty for the estimated texture classes. These outliers are stable, spatially and throughout the $\mathrm{CV}$ variants. These deviation hot spots can occur due to soils being out of the range of sampled soil types or specific land cover.

However, the automatically optimized choice of PCs for the regression estimators is quite constant throughout the sample data subsets in the different $\mathrm{CV}$ variants. For all three texture classes, PC2 is used by $100 \%$ of the estimator setups, the pattern that resembles geology. The main variation within the texture fractions is then added for

1. sand by using PC3 (99\% of the setups) and PC1 (65\%),

2. silt by using PC4 ( $81 \%$ of the setups) and PC5 (54\%) or PC1 $(47 \%)$,

3. clay by using PC3 (100\% of the setups) and PC4 $(84 \%)$,

with the number of different variants increasing with the size of the validation data. This also hints at a slight inconsistency within the measured data. Nonetheless, the overall estimator choice seems to be relatively uniform, especially for clay and sand fractions.

\section{Discussion and conclusion}

This study investigates the potential of estimating distributed soil texture fractions with time series of thermal remote sensing data. Elementary thermal patterns (PCs) are extracted from the time series with PCA and are used as inputs in a MLR model framework to estimate soil texture fractions. The MLRE model is calibrated and evaluated against a set of 212 measured soil texture data using four different CV variants. After calibration, it is applied for the generation of soil texture and soil type maps based on the distributed PCs information.

The MLRE prediction uncertainties expressed as overall RMSE when using the full data set for calibration is $12.7 \mathrm{pp}$ (sand-silt-clay: 16.2-13.0-7.1 pp) and does not change significantly with in different $\mathrm{CV}$ variants. Given local measurement uncertainties of $7.1 \mathrm{pp}$ for all fractions (sand-silt-clay: 8.7-7.8-4.9 pp), the model induced uncertainty component might be in the range of 3-8 pp, varying for the different fractions. The stability of RMSE and choice of PCs reveal 

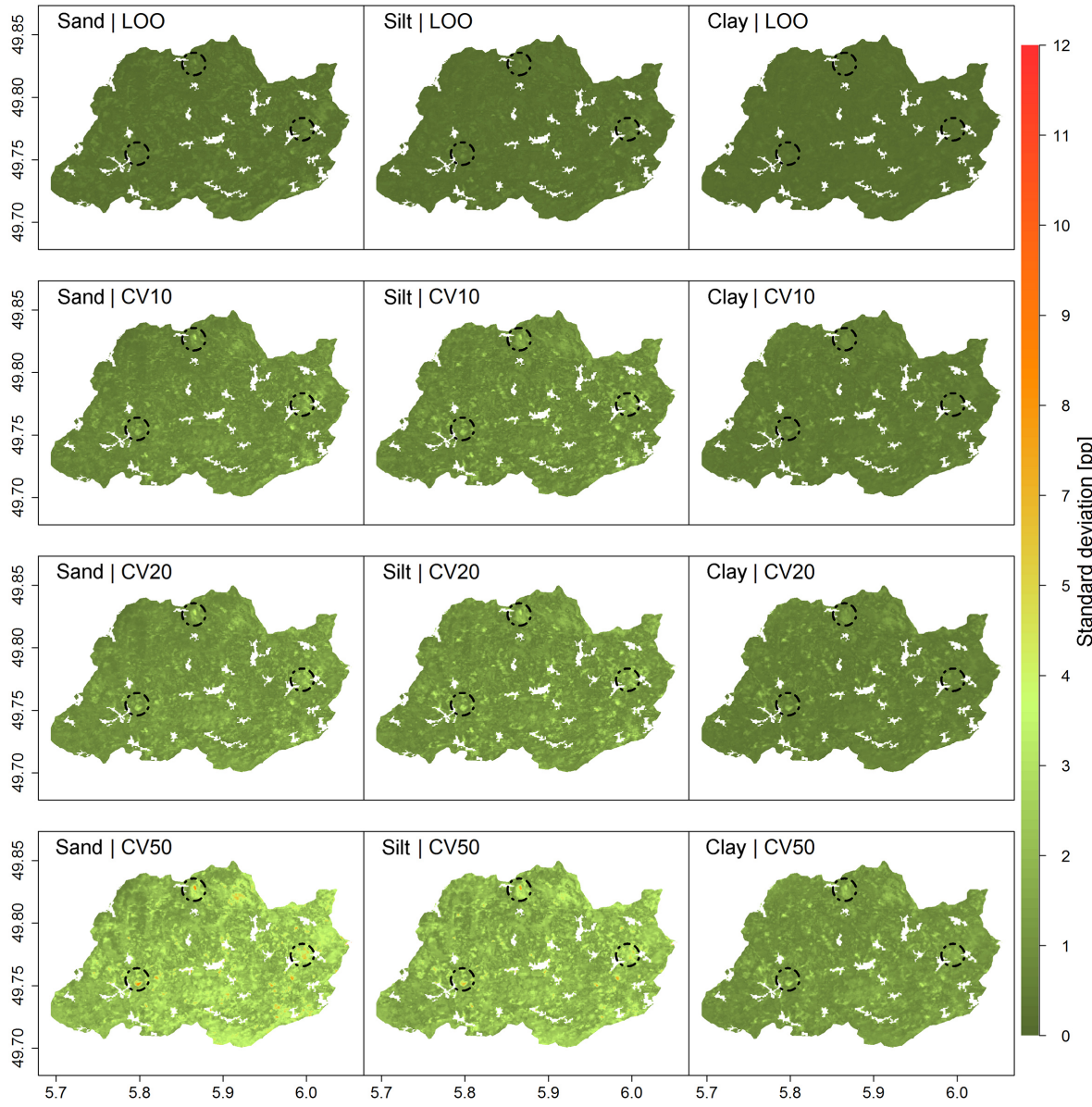

Figure 9. Spatial patterns of standard deviations for the different CV variants (rows) of soil texture fractions (columns) calculated from the estimators for the 212 different randomly selected data sets. Hotspots of high uncertainty ( $5 \mathrm{pp}$ and above; exemplary spots are circled on all 12 maps) can only be observed with CV50 subsets and within sand and silt fractions.

the reliability of this simple estimator setup, a distinct relation between the basic patterns, observed with thermal remote sensing, and the soil texture samples.

A review of different approaches presented in the literature, often using more complex methods or input data, reveals similar or even higher uncertainties. For example, McBratney et al. (2000) list RMSE for clay content based on 85 samples within an only 42 ha and less heterogeneous area. They test different estimator types in their work: 7.6-8.2 pp for interpolation methods and $6.2-8.9 \mathrm{pp}$ for regression techniques (regression trees to neural networks) with combinations of ancillary information (terrain data, yield data and electromagnetic measurements) with a resolution of $200 \mathrm{~m}$. The here presented MLRE based on PCs achieves similar uncertainty values for clay while using less complex methods and input in a more complex terrain. Wang et al. (2015) reach uncertainties of 10.7-15.5 pp for sand and 4.6-6.5 pp for clay, using a regression model on diurnal temperature range data from a derived land surface remote sensing product with a rather inapplicable coarse resolution of $1 \mathrm{~km}$ for a catchment of $5130 \mathrm{~km}^{2}$ with 62 soil samples. The product resulting from the MLRE approach is of higher resolution while providing similar deviations. Modeling soil texture inversely $(40 \mathrm{~m})$ from soil moisture, measured with a passive microwave radiometer, performed by Santanello et al. (2007) for a watershed of $148 \mathrm{~km}^{2}$, leads to RMSE values of 12$28 \mathrm{pp}$ for sand, $14-25 \mathrm{pp}$ for silt and $0-8 \mathrm{pp}$ for clay fractions. This inversion requires a complex model (Noah land surface model; Noah-LSM, 2015); however, it results in a much larger range of uncertainty. Overall, the herein presented estimator method requires the least temporal resolution of remote sensing data and least amount of additional data, notably none, with a simple regression method. Furthermore, the density of required measurements is low compared to the mentioned studies.

Our study also demonstrates that extracted PCs from time series of thermal images contain the necessary spatial information to delineate distributed soil texture information. The different $\mathrm{CV}$ variants show that an appropriate uncertainty range can be obtained with around 100 training samples for 
roughly $300 \mathrm{~km}^{2}$ with a target resolution of $15 \mathrm{~m}$. Analyzing the deviation maps for the different $\mathrm{CV}$ variants (Fig. 8) reveals hotspots of diverging relations between sample data and PCs. These maps can be used to further reduce uncertainty by localizing effective additional sample locations.

A different option, but presumably equally suitable, than using PCs is the direct delineation of thermal inertia maps from hydraulic soil properties for given time steps and soil moisture states, as shown in Murray and Verhoef (2007). This option requires the description of the same (amount of) spatially distributed soil hydraulic properties as used in pedotransfer functions and, therefore, does not simplify data collection.

The presented approach works well within the current resolution of $15 \mathrm{~m}$ and with a sparse temporal resolution, but should also work for different setups of spatial and temporal resolution, with a reasonable minimum variation in the time series. Hence, this approach is possible to handle many applications within hill slope, catchment, and up to continental extent with comparably small sampling effort and definite uncertainties.

The presented data can help to improve the generation of topsoil maps, especially without the need of proper soil genesis descriptions. These maps then can be utilized for mediumscale catchment setups of eco-hydrological models, especially within (near) ungauged basins. The basic thermal remote sensing time series can also be obtained from other sensors with different resolutions, such as Landsat (60-100 m) or MODIS $(1 \mathrm{~km})$. Only few measurements are necessary as long as the spatial extent of the thermal remote sensing data and taken samples cover the statistical distribution of catchment characteristics.

Further applications of this PCA-based MLRE to assess spatial distributions of bulk density, topsoil organic matter, vegetation density or even fraction of absorbed photosynthetic active radiation will be subject to further research. In addition, feasibility studies on the utilization of different remote sensing time series, ranging from microwave or visible imagery to mixed databases and comparison to model output are issues of ongoing studies.

\section{Data availability}

Original ASTER Level 1A data are freely available through the Reverb|Echo data base service (http://reverb.echo.nasa. gov/reverb/) from NASA's Earth Observing System Data and Information System (EOSDIS). The in situ soil texture data, auxiliary data, and results can be made available on request by contacting the authors or the CAOS project (http://www. caos-project.de/).

Acknowledgements. We want to thank the German Research Foundation (DFG) and the Austrian Science Fund (FWF) for funding this research through the CAOS (Catchments as Organised
Systems) Research Unit (DFG: FOR 1598, grant SCHU1271/5-1; FWF: I 2142-N29). We also want to thank the LPDAAC (Land Processes Distributed Active Archive Center) for providing free ASTER data. We thank Loes van Schaik, Elisabeth Thiem, Liya Sun and the student staff for their fieldwork and the laboratory analysis, especially, Thomas Weiss for his work in the LMU laboratory, as well as the Lippmann Research Institute, Luxembourg, for arranging access to the catchment.

Edited by: B. Su

Reviewed by: two anonymous referees

\section{References}

AAFC: Agriculture and Agri-Food Canada, The National Soil DataBase (NSDB), http://sis.agr.gc.ca/cansis/nsdb/index.html, last access: 17 July 2015.

Ahmed, Z. and Iqbal, J.: Evaluation of Landsat TM5 Multispectral Data for Automated Mapping of Surface Soil Texture and Organic Matter in GIS, Eur. J. Remote Sens., 47, 557-573, 2014.

Arlot, S. and Celisse, A.: A survey of cross-validation procedures for model selection, Stat. Surv., 4, 40-79, doi:10.1214/09-SS054, 2010.

Betts, A. K., Ball, J. H., Beljaars, A. C. M., Miller, M. J., and Viterbo, P. A.: The land surface-atmosphere interaction: A review based on observational and global modeling perspectives, J. Geophys. Res., 101, 7209-7225, 1996.

Box, G. E. P. and Cox, D. R.: An Analysis of Transformations, J. R. Stat. Soc. B, 26, 211-252, 1964.

CAOS: CAOS - Catchments as Organised Systems, http://www. caos-project.de, last access: 17 July 2015.

Chun, Y. and Griffith, D. A.: Spatial statistics and geostatistics: theory and applications for geographic information science and technology, SAGE Publications Ltd., London, 2013.

de Roo, A. P., Gouweleeuw, B., Thielen, J., Bartholmes, J., Bongioannini-Cerlini, P., Todini, E., Bates, P. D., Horrit, M., Hunter, N., Beven, K., Pappenberger, F., Heise, E., Rivin, G., Hils, M., Hollingsworth, A., Holst, B., Kwadijk, J., Reggiani, P., van Dijk, M., Sattler, K., and Sprokkereef, E.: Development of a European flood forecasting system, Int. J. River Basin Manage., 1, 49-59, 2003.

Dhawale, N. M., Adamchuk, V. I., Prasher, S. O., Viscarra Rossel, R. A., Ismail, A. A., and Kaur, J.: Proximal soil sensing of soil texture and organic matter with a prototype portable mid-infrared spectrometer, Eur. J. Soil Sci., 66, 661669, doi:10.1111/ejss.12265, 2015.

Durner, W. and Lipsius, K.: Determining Soil Hydraulic Properties, Encyclopedia of Hydrological Sciences, in: Chapter 75, edited by: Anderson, M. G. and McDonnell, J. J., John Wiley \& Sons, Ltd., Hoboken, NJ, 1121-1144, 2005.

EEA: CORINE Land Cover Project, published by Commission of the European Communities, http://www.eea.europa.eu/ publications/COR0-landcover (last access: 22 May 2014), 1995.

EOSDIS - NASA's Earth Observing System Data and Information System: ASTER Level 1A data, http://reverb.echo.nasa.gov/ reverb/, last access: September 2016.

FAO: Food and Agriculture Organization of the United Nations, FAO SOILS PORTAL, Harmonized World Soil 
Database v 1.2, http://www.fao.org/soils-portal/soil-survey/ soil-maps-and-databases/harmonized-world-soil-database-v12/ en/, last access: 17 July 2015.

Farouki, O. T.: Thermal Properties of Soils, CRREL Monogr., No. 81-1, US Army Cold Regions Research and Engineering Laboratory, Hanover, NH, 136 pp., 1982.

Franklin, J.: Computational Methods for Physics, Cambridge University Press, New York, 2013.

Fujisada, H.: Design and performance of ASTER instrument, in: Advanced and Next-Generation Satellites, Proceedings of SPIE, Paris, France, 15 December 1995, 16-25, doi:10.1117/12.228565, 1995.

Hall, F. G., Townshend, J. R., and Engman, E. T.: Status of remote sensing algorithms for estimation of land surface state parameters, Remote Sens. Environ., 51, 138-156, 1995.

ISO 11277: Soil quality - Determination of particle size distribution in mineral soil material - Method by sieving and sedimentation, 2009.

ISRIC: International Soil Reference and Information Centre, Soil and Terrain Database (SOTER) Programme, http://www.isric. org/projects/soil-and-terrain-database-soter-programme, last access: 17 July 2015.

JRC: Joint Research Centre, European Soil Portal - Soil Data and Information Systems, http://eusoils.jrc.ec.europa.eu/, last access: 17 July 2015.

McBratney, A. B., Odeh, I. O., Bishop, T. F., Dunbar, M. S., and Shatar, T. M.: An overview of pedometric techniques for use in soil survey, Geoderma, 97, 293-327, 2000.

Minacapilli, M., Cammalleri, C., Ciraolo, G., D’Asaro, F., Iovino, M., and Maltese, A.: Thermal inertia modeling for soil surface water content estimation: A laboratory experiment, Soil Sci. Soc. Am. J., 76, 92-100, 2012.

Müller, B., Bernhardt, M., and Schulz, K.: Identification of catchment functional units by time series of thermal remote sensing images, Hydrol. Earth Syst. Sci., 18, 5345-5359, doi:10.5194/hess-18-5345-2014, 2014.

Murray, T. and Verhoef, A.: Moving towards a more mechanistic approach in the determination of soil heat flux from remote measurements: I. A universal approach to calculate thermal inertia, Agr. Forest Meteorol., 147, 1-2, doi:10.1016/j.agrformet.2007.07.004, 2007.

Noah-LSM: Land-Surface Modeling: The Community Noah Land Surface Model (LSM), http://www.ral.ucar.edu/research/land/ technology/lsm.php, last access: 21 October 2015.

Osborne, J. W.: Improving your data transformations: Applying the Box-Cox transformation, Pract. Assess. Res. Eval., 15, 1-9, 2010 .
Pachepsky, Y. and Rawls, W. J. (Eds.): Development of pedotransfer functions in soil hydrology, Vol. 30, Developments in Soil Science, Elsevier, Amsterdam, 2004.

Reed, S., Schaake, J., and Zhang, Z.: A distributed hydrologic model and threshold frequency-based method for flash flood forecasting at ungauged locations, J. Hydrol., 337, 402-420, doi:10.1016/j.jhydrol.2007.02.015, 2007.

Rees, G. and Rees, W. G.: Physical principles of remote sensing, Cambridge University Press, New York, 2013.

Sadler, E. J., Busscher, W. J., Bauer, P. J., and Karlen, D. L.: Spatial scale requirements for precision farming: A case study in the southeastern USA, Agron. J., 90, 191-197, 1998.

Sakia, R. M.: The Box-Cox transformation technique: a review, J. R. Stat. Soc. D, 41, 169-178, 1992.

Santanello, J. A., Peters-Lidard, C. D., Garcia, M. E., Mocko, D. M., Tischler, M. A., Moran, M. S., and Thoma, D. P.: Using remotely-sensed estimates of soil moisture to infer soil texture and hydraulic properties across a semi-arid watershed, Remote Sens. Environ., 110, 79-97, 2007.

Selige, T., Böhner, J., and Schmidhalter, U.: High resolution topsoil mapping using hyperspectral image and field data in multivariate regression modeling procedures, Geoderma, 136, 235-244, doi:10.1016/j.geoderma.2006.03.050, 2006.

SGL: Carte Géologique du Luxembourg, Feuille No. 7, Redange, $1: 25.000$, R. Colpach, Service Géologique du Luxembourg, Luxembourg, 2003.

SPP: Sols des plateaux et des pentes, Scale $1: 100.000$, Ministère de l'agriculture, de la viticulture et du développement rural, Administration des services techniques de l'agriculture, Service de pédologie, Grand-Duché de Luxembourg, 1969.

USDA: United States department of Agriculture, Natural Resources Conservation service, Web Soil Survey, http://websoilsurvey.sc. egov.usda.gov/App/HomePage.htm, last access: 17 July 2015.

Wang, D. C., Zhang, G. L., Zhao, M. S., Pan, X. Z., Zhao, Y. G., Li, D. C., and Macmillan, B.: Retrieval and Mapping of Soil Texture Based on Land Surface Diurnal Temperature Range Data from MODIS, PloS One, 10, e0129977, doi:10.1371/journal.pone.0129977, 2015.

Zehe, E., Ehret, U., Pfister, L., Blume, T., Schröder, B., Westhoff, M., Jackisch, C., Schymanski, S. J., Weiler, M., Schulz, K., Allroggen, N., Tronicke, J., van Schaik, L., Dietrich, P., Scherer, U., Eccard, J., Wulfmeyer, V., and Kleidon, A.: HESS Opinions: From response units to functional units: a thermodynamic reinterpretation of the HRU concept to link spatial organization and functioning of intermediate scale catchments, Hydrol. Earth Syst. Sci., 18, 4635-4655, doi:10.5194/hess-18-4635-2014, 2014. 